\title{
A Jocic-type approach for a practical and scalable synthesis of pyrrolonaphthoxazepine (PNOX)-based potent proapoptotic agents
}

\author{
Stefano Federico ${ }^{\mathrm{a}, \mathrm{b}}$, Tuhina Khan ${ }^{\mathrm{a}}$, Nicola Relitti ${ }^{\mathrm{a}}$, Giulia Chemi ${ }^{\mathrm{a}, \mathrm{b}}$, Margherita Brindisi ${ }^{\mathrm{a}, \mathrm{b}, *}$, \\ Simone Brogi ${ }^{\mathrm{a}, \mathrm{b}, \mathrm{c}}$, Ettore Novellino ${ }^{\mathrm{c}}$, Daniela M. Zisterer ${ }^{\mathrm{d}}$, Giuseppe Campiani ${ }^{\mathrm{a}, *}$, Sandra Gemma ${ }^{\mathrm{a}, \mathrm{b}}$, \\ Stefania Butini ${ }^{\mathrm{a}, \mathrm{b}}$ \\ ${ }^{a}$ Department of Biotechnology, Chemistry and Pharmacy, DoE 2018-2022, University of Siena, Via Aldo Moro, 2, 53100 Siena, Italy \\ ${ }^{\mathrm{b}}$ Istituto Toscano Tumori, University of Siena, via Aldo Moro 2, I-53100, Siena, Italy \\ ' Dipartimento di Farmacia, DoE 2018-2022, University of Naples Federico II, via D. Montesano 49, 80131 Naples, Italy \\ ${ }^{\mathrm{d}}$ School of Biochemistry and Immunology, Trinity Biomedical Sciences Institute, Trinity College Dublin, 152-160 Pearse Street, Dublin 2, Ireland
}

\section{A R T I C L E I N F O}

\section{Article history:}

Received 7 September 2018

Revised 30 October 2018

Accepted 4 November 2018

Available online $\mathrm{xxxx}$

\section{Keywords:}

Pyrrolonaphthoxazepines

Jocic reaction

Aryl-alkyl ethers

Antitumor agents

\begin{abstract}
A B S T R A C T
We developed a Jocic-type protocol for the construction of the pyrrolonaphthoxazepine (PNOX) core. After an initial investigation based on the isolation of a trichloromethyl carbinol derivative, we shifted our attention towards a multicomponent single-step protocol. Screening of a variety of bases and solvents led to the identification of the optimum conditions for the preparation of the key $\alpha$-aryloxy carboxylic acids to undergo intramolecular cyclization. The novel chemical route significantly improved overall yields for the preparation of PNOX-based compounds and was successfully extended to the preparation of 1,4-benzoxazinone-based templates.
\end{abstract}

(c) 2018 Published by Elsevier Ltd.
Pyrrolo-1,5-benzoxazepines (PBOXs) and pyrrolonaphthoxazepines (PNOXs) are pharmaceutically relevant heterocycles. As a part of our research activity, a major focus was directed toward the development of novel PBOXs and PNOXs as potent antitumor agents, inhibitors of adenosine kinase and nonnucleoside inhibitors of human immunodeficiency virus reverse transcriptase (HIV-1 RT) [1-12]. In particular, our continuing efforts in the field of antitumor agents led to the development of PBOX- and PNOXbased compounds as potent proapoptotic agents [4]. Several members of this latter class of compounds were shown to potently inhibit the growth of a number of cancer cell lines. In addition, a number of PBOXs and PNOXs were effective in ex vivo patient samples from chronic lymphocytic leukemia (CLL), chronic myeloid leukemia (CML) and multiple myeloma (MM) and in in vivo tumor models of breast cancer and CML with limited effects in normal cells $[13,14]$. Among the developed analogues, PNOX derivative 1a (Fig. 1) stood out as extremely potent proapoptotic agent, also demonstrating interesting radiosensitizing properties in glioblastoma and prostatic cancer cell lines [15]. Thus, compound 1a became our prototype for the development of optimized PNOX

\footnotetext{
* Corresponding authors.

E-mail addresses: margherita.brindisi@unisi.it (M. Brindisi), campiani@unisi.it (G. Campiani).
}

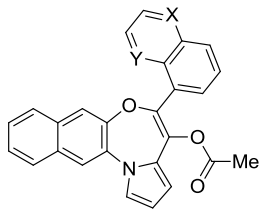

1a, PNOX, $\mathrm{X}=\mathrm{Y}=\mathrm{CH}$;

1b, NF2258, $X=\mathrm{N}, \mathrm{Y}=\mathrm{CH}$

1c, NF2173, $X=C H, Y=N$.

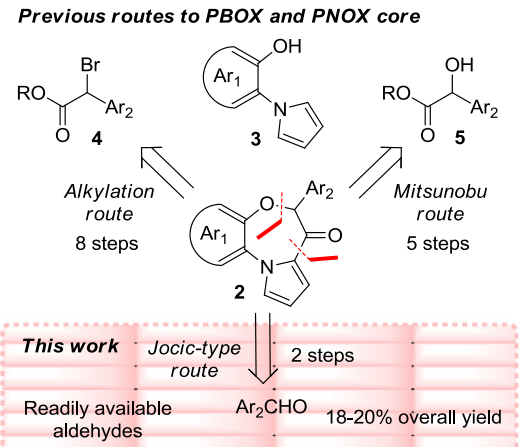

Fig. 1. Representative PNOX derivatives, previous retrosynthetic analysis and newly proposed Jocic-type approach. 
derivatives. With the aim of further improving PNOXs in terms of antitumor potency and drug-like properties and to fully elucidate their mechanism of action, we modified the PNOX scaffold at different levels. In particular, we aimed at reducing the high lipophilicity of the early developed analogues typified by 1a, by introducing specific structural modifications such as heteroatoms. Accordingly, a small series of analogues were designed by replacing the terminal naphthyl moiety with a quinolyl system in which a number of nitrogen positions and quinoline ring decorations were explored. Among them, compounds 1b,c were developed bearing a 5-quinolyl and a 8-quinolyl system, respectively. Both compounds showed excellent proapoptotic potential in a relevant panel of tumor cell lines (including multidrug-resistant cell lines) and displayed a superior drug-like profile with respect to prototypic compound 1a [16].

As represented in Fig. 1, the cyclic ketone PNOX template (2) could derive from an alkylation reaction between pyrrolylphenol derivatives (3) and the suitable $\alpha$-bromo esters (4) providing the aryl-alkyl ether skeleton to undergo intramolecular cyclization on the pyrrole $\alpha$-position.

Due to the lengthy and often problematic synthesis of $\alpha$-bromopheylacetic derivatives of quinolines and other heterocycles, we later on envisioned a Mitsunobu-based route for the construction of the key aryl-alkyl ether template. Accordingly, a glyoxylate intermediate could represent a new and convenient access to the required $\alpha$-hydroxyester derivatives (5) to undergo Mitsunobu reaction with the pyrrolylphenol derivatives (3). This revised path provided a 3-step shorter route to the desired PNOX template $\mathbf{2}$, with respect to the original one [16]. However, both the designed routes displayed a number of drawbacks which led to unsatisfactory overall yields for the preparation of the target PNOX-based compounds, thus compromising a large scale preparation. Both alkylation and Mitsunobu routes involved the treatment of an aryl bromide (9) with $n$-butyllithium in order to insert the $\alpha$-carbon atom to serve as the handle for appending the required $\alpha$-bromo or $\alpha$-hydroxy functionalities for aryl-alkyl ether construction (Fig. 2). In particular, for the alkylation route, the preparation of the $\alpha$-bromo quinolylacetic esters (4) started from the suitable aldehydes (7) easily accessible by treatment with dry $\mathrm{N}, \mathrm{N}$ dimethylformamide in the presence of $n$-butyllithium. The additional carbon unit was then inserted by Wittig homologation leading to the formation of the corresponding enolether which, upon

\section{A) Alkylation route}

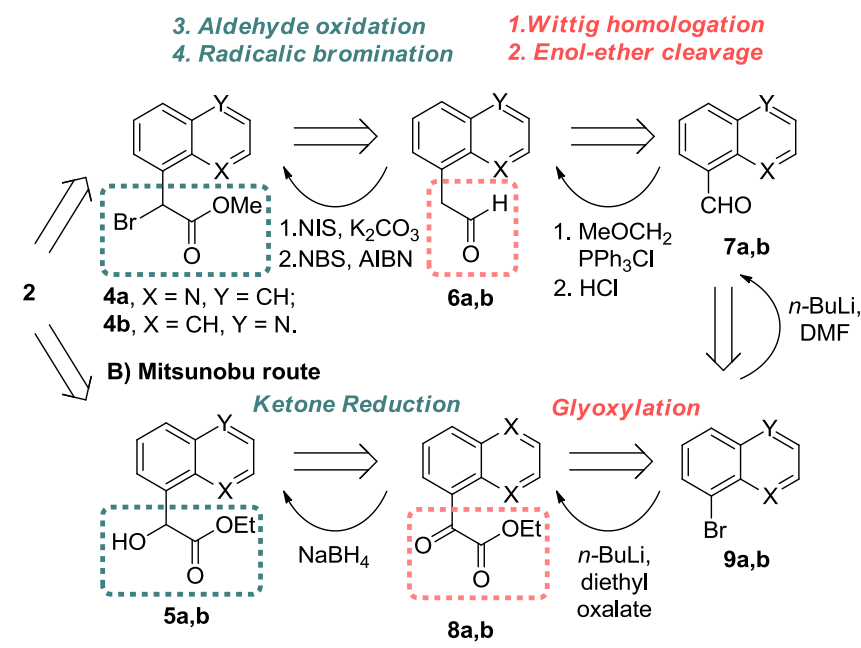

Fig. 2. Outline of the synthesis of the key $\alpha$-bromo derivatives $\mathbf{4}$ and $\alpha$-hydroxy derivatives 5, key intermediates for the construction of PNOX scaffold $\mathbf{2}$, according to the previously employed alkylation and Mitsunobu routes. treatment with aqueous hydrochloric acid, afforded the homologated aldehyde $(\mathbf{6})$.

Following oxidation to the corresponding methylester derivative was performed with $\mathrm{N}$-iodosuccinimide and methyl iodide in the presence of potassium carbonate. The oxidation step, as well as the subsequent radical bromination, usually displayed moderate yield, which finally provided the desired $\alpha$-bromo derivatives in 5 steps (overall yield 15\%, Fig. 2A). The Mitsunobu route, although shorter and apparently more straightforward, displayed several pitfalls. First, the insertion of the glyoxalyl moiety by reaction with ethyl chlorooxoacetate in the presence of $n$-butyllithium led to a series of side products with consequent tedious purifications and poor yields. Most importantly, the simultaneous presence of keto and ester functionalities led to the concomitant over-reduction to the corresponding diol (overall yield 6\%, Fig. 2B). The over-reduction took place to different extents most likely depending on substrate, temperature, time and reaction scale and, very often, in a rather unpredictable fashion. Also, the Mitsunobu reaction itself displayed only moderate yields not suitable for large scale applications and led to the formation of a significant number of side products.

In view of the excellent antitumor potential of compounds 1a-c, we aimed at identifying a more general and expedite chemical strategy to target compounds, also suitable for scale-up for in vivo assessment. Thus, we sought to plan a more straightforward strategy overcoming the issues related to the overlong and lowyielding functionalization especially with respect to the quinolyl moiety. To this end, we envisaged a Jocic-type approach as a versatile and efficient option for the rapid synthesis of templates with significant structural diversity and complexity. In our context, it could represent an ingenious and convenient shortcut for the construction of key $\alpha$-aryloxy carboxylic acids $\mathbf{1 5}$ (Fig. 3 ) as the direct substrate for intramolecular Friedel-Crafts leading to the desired cyclic ketones $\mathbf{2}$ as reported [4,17].

Accordingly, the process would employ the suitable aldehyde to be promptly converted into the corresponding trihalomethyl carbinol and a phenol derivative to function as the nucleophile. As shown in Fig. 3, our conceived carbinol would undergo conversion into the corresponding gem-dihaloepoxide which, upon attack of the phenoxide nucleophile, would provide the corresponding acyl halide, immediately converted in the reaction medium into the desired carboxylic acid [18-21].

The Jocic-Reeve reaction involves the deprotonation of a trihalomethyl carbinol (11), routinely prepared in one step from the corresponding aldehyde (10), [22] by a base in protic media to
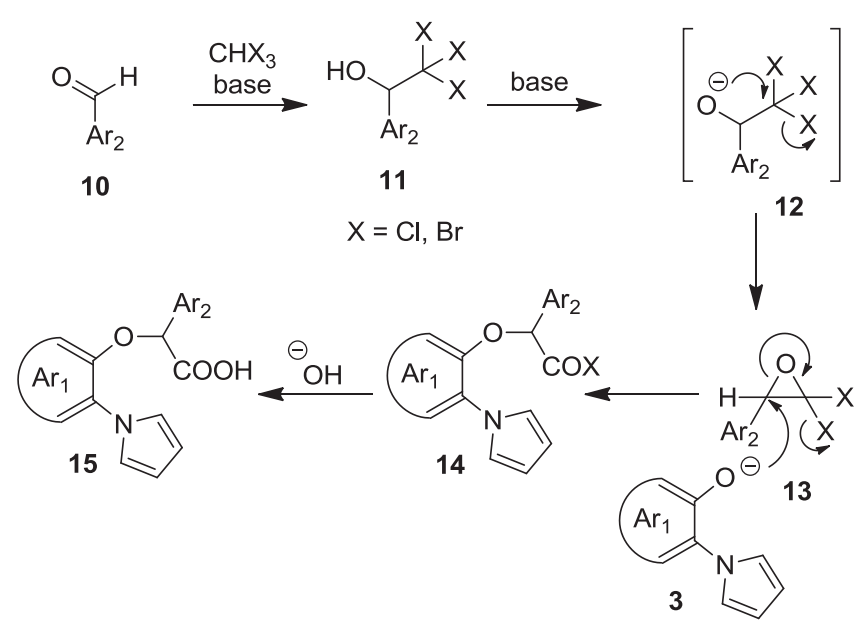

Fig. 3. Designed Jocic-type path to the carboxylic acid derivative 15, key intermediate for the synthesis of the PBOX and PNOX cores. 
generate a reactive gem-dihalo-epoxide (13) (Fig. 3). The epoxide readily undergoes a regioselective substitution reaction with the added nucleophile, to afford the corresponding $\alpha$-substituted acyl halide intermediate (14), finally generating the carboxylic acid $\mathbf{1 5}$ upon nucleophilic acyl substitution. Variations of the original Jocic reaction, including the popular Corey-Link reaction $[23,24]$, have been the basis for a variety of new synthetic methods and served as featured steps in target-directed synthesis [25-28] and in drug discovery and development [29-35].

Bearing those factors in mind, and in order to assess the feasibility of our newly proposed approach, we conducted a preliminary investigation preparing the trichloromethyl carbinol derivatives of 1-naphthyl and 5-quinolyl aldehydes using 3 different methodologies [36]. The first method (Condition 1, Table S1) employed the methodology reported by Corey and Link [37]; the second method (Condition 2, Table S1) exploited a solventless procedure firstly proposed by Aggarwal [38]; the third method (Condition 3, Table S1) involved the Wyvratt method employing potassium hydroxide in the presence of chloroform and methanol [39]. All the three adopted procedures provided the desired carbinols in nearly quantitative yields, with only a quick filtration on a silica gel pad needed to obtain satisfactory degrees of purity. However, all the subsequent attempts to convert the carbinols into the desired aryloxy carboxylic acids (summarized in Table S1) did not lead to the desired products. All the employed conditions, using $\mathrm{NaOH}, \mathrm{KOH}$ and $\mathrm{NaH}$ as the base and a variety of solvent systems (Table S1, entries 1-11) did not allow the isolation of the desired carboxylic acids, but led instead to complex mixtures of byproducts (Table S1, entries 7 and 8 ) or recovery of unreacted starting material (Table S1, entries 1-6 and 9).

This first set of attempts, although unsuccessful, resulted useful to shift our mindset towards a multicomponent approach involving the addition of an aryl aldehyde to a trihalomethide (formed by deprotonation of a haloform with a base) and resulting in an $\alpha$-trihalomethyl alkoxide evolving into the gem-dihaloepoxide without necessitating the isolation of the carbinol. A challenge associated with the setting up of our procedure was the selection of a proper solvent system (protic solvent or mixed media) compatible with our phenoxide nucleophile. In addition, since most protic solvents may also function as nucleophiles, especially in the presence of the hydroxide, the intended nucleophile must outcompete the milieu of base, solvent, conjugate base of the solvent, and halide for nucleophilic substitution.

Also, we were aware of the significant possibility of dealing with a competing Cannizzaro reaction involving the starting aryl aldehyde when selecting hydroxides as the preferential base [38].

Accordingly, we identified a series of focused attempts to be performed based on both literature data and on our longstanding experience in manipulating $\alpha$-aryloxycarboxylic acid templates. Our experiments are summarized in Table 1. First of all, we investigated the outcome of a single-pot system (entries 1-8, Table 1) on 1-naphthyl, 5-quinolyl and 8-quinolyl aldehydes by using sodium hydroxide as the base and bromoform as the halogen source. Interestingly, this attempt offered us the desired acids for 1-naphthyl (entry 2, Table 1) and 5-quinolyl (entry 5, Table 1) systems with good yields but remained unsuccessful for the 8-quinolyl aldehyde (entry 6 , Table 1 ). A longer reaction time along with a modified equivalency (entry 7 and 8 , Table 1 ) of the starting materials appeared to be unsatisfactory for this system, resulting in poor yield (entry 7, Table 1) or in a complex mixture of byproducts (entry 8, Table 1). Moreover, starting materials were recovered in good extent for almost all the reactions involving the 8-quinolyl system.

Relying on the mechanistic understanding of the Jocic-Reeve reaction pathway, we also tried to explore this procedure in a two-pot system (entry 9 to 14, Table 1 ). However, it could not offer us a better outcome, which was also complicated by the lack of reproducibility (entry 11 , Table 1 ).

Table 1

Reaction conditions explored for the Jocic-type synthesis of aryloxy carboxylic acids $\mathbf{1 5}$

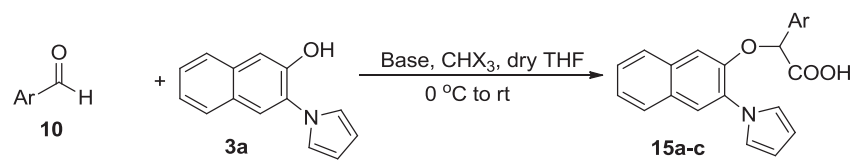

\begin{tabular}{|c|c|c|c|c|c|c|c|c|}
\hline Entry $^{\mathrm{a}}$ & Method $^{\mathrm{b}, \mathrm{c}}$ & $\mathrm{Ar}$ & 3a (equiv.) & $\mathrm{X}$ (equiv.) & Base (equiv.) & Temp $\left({ }^{\circ} \mathrm{C}\right)^{\mathrm{d}}$ & Time $(h)^{e}$ & Yield $(\%)^{\mathrm{f}}$ \\
\hline 1 & $A^{b}$ & 1-Naphthyl & 0.3 & $\operatorname{Br}(1.7)$ & $\mathrm{NaOH}(1.7)$ & $\mathrm{rt}$ & 6 & 4 \\
\hline 2 & & & 0.3 & $\operatorname{Br}(1.7)$ & $\mathrm{NaOH}(1.7)$ & $\mathrm{rt}$ & 12 & 48 \\
\hline 3 & & & 1.0 & $\operatorname{Br}(1.7)$ & $\mathrm{NaOH}(1.7)$ & $\mathrm{rt}$ & 12 & 3 \\
\hline 4 & & & 1.0 & $\operatorname{Br}(5.0)$ & $\mathrm{NaOH}(5.0)$ & $\mathrm{rt}$ & 12 & - \\
\hline 5 & & 5-Quinolyl & 0.3 & $\operatorname{Br}(1.7)$ & $\mathrm{NaOH}(1.7)$ & $\mathrm{rt}$ & 12 & 28 \\
\hline 6 & & 8-Quinolyl & 0.3 & $\operatorname{Br}(1.7)$ & $\mathrm{NaOH}(1.7)$ & $\mathrm{rt}$ & 12 & - \\
\hline 7 & & & 0.3 & $\operatorname{Br}(1.7)$ & $\mathrm{NaOH}(1.7)$ & $\mathrm{rt}$ & 48 & 5 \\
\hline 8 & & & 0.5 & $\operatorname{Br}(1.7)$ & $\mathrm{NaOH}(1.7)$ & $\mathrm{rt}$ & 36 & - \\
\hline 9 & $\mathrm{~B}^{\mathrm{c}}$ & 1-Naphthyl & 0.3 & $\operatorname{Br}(1.7)$ & $\mathrm{NaOH}(1.7)$ & $\mathrm{rt}$ & 6 & 11 \\
\hline 10 & & & 0.3 & $\operatorname{Br}(1.7)$ & $\mathrm{NaOH}(1.7)$ & $\mathrm{rt}$ & 12 & 20 \\
\hline 11 & & & 0.5 & $\operatorname{Br}(1.7)$ & $\mathrm{NaOH}(1.7)$ & $\mathrm{rt}$ & 12 & $37^{g}$ \\
\hline 12 & & & 1.0 & $\mathrm{Br}(5.0)$ & $\mathrm{NaOH}(5.0)$ & $\mathrm{rt}$ & 12 & - \\
\hline 13 & & & 0.5 & $\operatorname{Br}(1.7)$ & $\mathrm{Cs}_{2} \mathrm{CO}_{3}(1.7)$ & $\mathrm{rt}^{\mathrm{h}}$ & 72 & - \\
\hline 14 & & & 0.3 & $\mathrm{Cl}(1.7)$ & $\mathrm{NaOH}(1.7)$ & $50^{i}$ & 14 & - \\
\hline
\end{tabular}

${ }^{a}$ Reactions were conducted with 1 equivalent of corresponding aldehyde in dry THF medium except for entry 11 (2 drops of DMF added to THF solution).

b Phenol was treated with the base and the aldehyde followed by the haloform in a single pot system.

c Phenol and the aldehyde, along with the haloform were treated in two separate flasks followed by the transferring of the phenoxide system to the aldehyde and haloform solution.

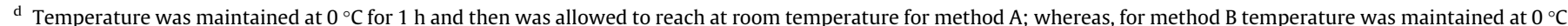

for $1 \mathrm{~h}$ before and $1 \mathrm{~h}$ after the transferring of the phenoxide system except for entries 13 and 14

e Reaction time after reaching at room temperature.

f Isolated yield of purified product.

g Not reproducible and not scalable.

h Temperature was maintained at $0^{\circ} \mathrm{C}$ for $3 \mathrm{~h}$ before and $1 \mathrm{~h}$ after the transferring of the phenoxide system.

i Temperature was maintained at $0{ }^{\circ} \mathrm{C}$ for $1 \mathrm{~h}$ before and $1 \mathrm{~h}$ after the transferring of the phenoxide system and was increased to $50{ }^{\circ} \mathrm{C}$ for $2 \mathrm{~h}$. 
For both the attempts, 1-naphthyl and 5-quinolyl systems produced a considerable amount of Cannizzaro side products. Application of a milder alkaline system (entry 13, Table 1 ) in order to reduce this particular disadvantage was not helpful as it could not offer the desired $\alpha$-aryloxycarboxylic acid.

Acids 15a,b were submitted to intramolecular Friedel-Crafts cyclization with phosphorous pentachloride in dry dichloromethane as reported (Scheme 1) [4,17]. The average overall yield for obtaining cyclic ketones 2a,b was $18-20 \%$ over 2 steps. The yield to obtain the same cyclic ketone with previous methodologies was $0.6 \%$ for ketone $\mathbf{2 b}$ over 5 steps.

To further broaden the scope and extend the utility of our protocol, we envisaged its application to the construction of 1,4-benzoxazinone- and benzothiazinone-based scaffolds. We were particularly interested in these templates due to our recent discover of their utility as dual inhibitors of GSK3 $\beta$ and adenosine kinase enzymes [6]. Beyond our specific interest, these structural templates are present in many drugs and are widely used for medicinal chemistry applications. There are hardly any literature reports about application on Jocic-type protocols for the construction of 1,4-benzoxa(thia)zinone cores. The few available reports rely upon the reaction of trichloromethyl carbinols with aminophenols directly leading to the cyclized 1,4-benzoxazinone templates in low yields. However, the yields of these reactions in the reported conditions were strongly affected by the presence of competing nucleophiles [40].

We preliminarily interrogated the efficacy of our protocol using thiophenol nucleophiles 17a-c (Table 2, entries 1-3). The reaction between thiophenol (17a) and benzaldehyde provided the desired $\alpha$-aryloxycarboxylic acid 18a in $27 \%$ yield, while the presence of a $p-\mathrm{NO}_{2}$ functionality (17b) led to a slightly decreased yield (19\%) for the corresponding acid $\mathbf{1 8 b}$. We then applied our protocol to 0 aminothiophenol 17c (Table 2, entry 3). To our delight, the reaction led to the formation of the 1,4-benzothiazinone derivative 19a in $48 \%$ yield. However, the same protocol did not provide comparable

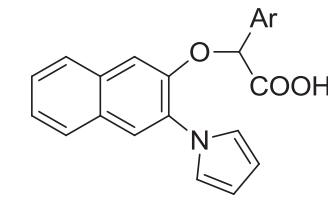

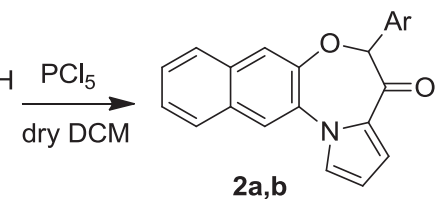

15a $\mathrm{Ar}=1$-naphthyl

15b Ar $=5$-quinolyl

Scheme 1. Synthesis of cyclic ketones $\mathbf{2 a , b}$ from $\alpha$-aryloxycarboxylic acid deriving from Jocic-type protocol approach. results when applied to the 0 -aminophenol 17d, affording the corresponding 1,4-benzoxazinone derivative 19b only in $7 \%$ yield (Table 2, entry 4). As a further application, we employed our developed protocol to convert phenylpyrrole derivative 17e (Table 2 , entry 5 ) to the corresponding $\alpha$-aryloxycarboxylic acid derivative $\mathbf{1 8 c}$, in order to verify the compatibility of our method with basic amine functionalities to be potentially inserted into our PNOX templates. In particular, we explored a cyclic amine ( $N$-Me piperazine) as a frequently executed approach in medicinal chemistry for attaining water solubility of the target compounds. As shown in Table 2, the reaction proceeded smoothly providing the desired acid $\mathbf{1 8 c}$ in $37 \%$ yield.

The low yield obtained for the synthesis of 1,4-benzoxazinone scaffold 19b prompted us to attempt a slight modification of the route in order to improve the yield for this template. We sought to give up the one-pot approach, in favor of a two-step process involving the Jocic reaction performed on the corresponding $o$-nitrophenol derivative, and the subsequent reduction of the nitro functionality, immediately prompting intramolecular amide formation thus generating the cyclic 1,4-benzoxazinone scaffold. We employed for this investigation phenols 20a,b and aldehydes 16a,b, significant to our medicinal chemistry projects (Scheme 2). Desired carboxylic acids 21a-c were obtained (in 26-28\% yield), and the subsequent reduction in the presence of iron powder and ammonium chloride rapidly afforded the desired 1,4-benzoxazinone core.

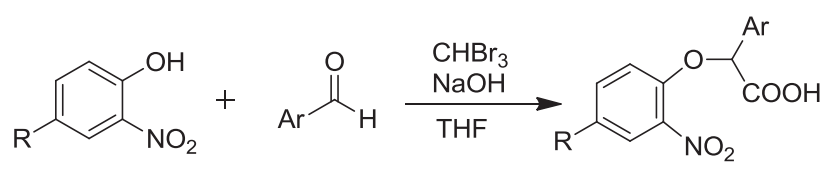

20a, $\mathrm{R}=\mathrm{H} \quad 16 \mathrm{a}, \mathrm{Ar}=$ phenyl 20b, R = vinyl 16b, Ar = 1-naphthyl

21a, $R=H, A r=$ phenyl 21b, $R=H, A r=$ naphthyl 21c, $R=$ vinyl, Ar = naphthyl<smiles>[R]c1ccc2c(c1)NC(=O)C([Al])O2</smiles>

$19 b, 22 a, b$

Scheme 2. Synthesis of 1,4-benzoxazinones $\mathbf{1 9 b}$ and 22a,b exploiting a Jocic-type protocol.

Table 2

Jocic-type protocol application to diverse phenol and thiophenol nucleophiles.

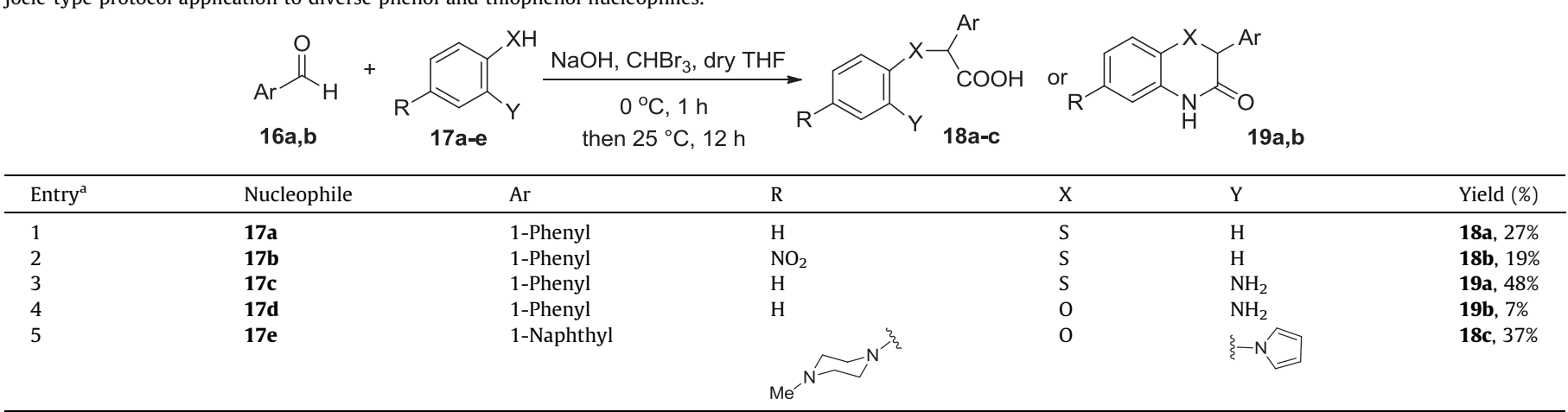

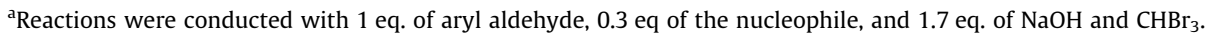




\section{Conclusion}

In this letter we describe for the first time the synthesis of PNOX-based scaffolds employing a Jocic-type route. Our screening of a variety of reaction conditions led to the identification of a reliable protocol which allowed a straightforward and scalable route for the preparation of our PNOX-based antitumor compounds for animal studies. We strongly reduced the number of steps to the title compounds and significantly improved the overall yield for the construction of key cyclic ketone core. We have further broadened the scope of our study and successfully extended our protocol to the synthesis of a small set of 1,4-benzoxa(thia)zinones.

\section{Acknowledgments}

This work has received funding from the European Union's Horizon 2020 research and innovation programme under the Marie Sklodowska-Curie Grant agreement No 721906.

\section{Appendix A. Supplementary data}

Supplementary data to this article can be found online at https://doi.org/10.1016/j.tetlet.2018.11.005.

\section{References}

[1] S.M. Nathwani, L.M. Greene, S. Butini, G. Campiani, D.C. Williams, A. Samali, E. Szegezdi, D.M. Zisterer, Int. J. Oncol. 49 (2016) 74-88.

[2] G. Campiani, I. Fiorini, M.P. De Filippis, S.M. Ciani, A. Garofalo, V. Nacci, G. Giorgi, A. Sega, M. Botta, A. Chiarini, R. Budriesi, G. Bruni, M.R. Romeo, C. Manzoni, T. Mennini, J. Med. Chem. 39 (15) (1996) 2922-2938.

[3] F.T. Bane, J.H. Bannon, S.R. Pennington, G. Campiani, D.C. Williams, D.M Zisterer, M.M. Mc Gee, J. Pharmacol. Exp. Ther. 329 (2009) 38-47.

[4] M.M. Mc Gee, S. Gemma, S. Butini, A. Ramunno, D.M. Zisterer, C. Fattorusso, B. Catalanotti, G. Kukreja, I. Fiorini, C. Pisano, C. Cucco, E. Novellino, V. Nacci, D.C. Williams, G. Campiani, J. Med. Chem. 48 (2005) 4367-4377.

[5] L.M. Greene, S. Butini, G. Campiani, D.C. Williams, D.M. Zisterer, J. Cancer 7 (2016) 2367-2377.

[6] S. Brogi, A. Ramunno, L. Savi, G. Chemi, G. Alfano, A. Pecorelli, E. Pambianchi, P. Galatello, G. Compagnoni, F. Focher, G. Biamonti, G. Valacchi, S. Butini, S. Gemma, G. Campiani, M. Brindisi, Eur. J. Med. Chem. 138 (2017) 438-457.

[7] L. Savi, M. Brindisi, G. Alfano, S. Butini, V. La Pietra, E. Novellino, L. Marinelli, A Lossani, F. Focher, C. Cavella, G. Campiani, S. Gemma, Chem. Biol. Drug Des. 87 (2016) 112-120.

[8] S. Butini, S. Gemma, M. Brindisi, G. Borrelli, A. Lossani, A.M. Ponte, A. Torti, G. Maga, L. Marinelli, V. La Pietra, I. Fiorini, S. Lamponi, G. Campiani, D.M. Zisterer S.M. Nathwani, S. Sartini, C. La Motta, F. Da Settimo, E. Novellino, F. Focher, J. Med. Chem. 54 (2011) 1401-1420.

[9] S. Butini, S. Gemma, M. Brindisi, G. Borrelli, I. Fiorini, A. Samuele, A. Karytinos, M. Facchini, A. Lossani, S. Zanoli, G. Campiani, E. Novellino, F. Focher, G. Maga, Bioorg. Med. Chem. Lett. 21 (2011) 3935-3938.

[10] S. Butini, M. Brindisi, S. Cosconati, L. Marinelli, G. Borrelli, S.S. Coccone, A. Ramunno, G. Campiani, E. Novellino, S. Zanoli, A. Samuele, G. Giorgi, A Bergamini, M. Di Mattia, S. Lalli, B. Galletti, S. Gemma, G. Maga, J. Med. Chem. 52 (2009) 1224-1228
[11] S. Zanoli, S. Gemma, S. Butini, M. Brindisi, B.P. Joshi, G. Campiani, C. Fattorusso, M. Persico, E. Crespan, R. Cancio, S. Spadari, U. Hubscher, G. Maga, Biochem. Pharmacol. 76 (2008) 156-168.

[12] C. Fattorusso, S. Gemma, S. Butini, P. Huleatt, B. Catalanotti, M. Persico, M. De Angelis, I. Fiorini, V. Nacci, A. Ramunno, M. Rodriquez, G. Greco, E. Novellino, A. Bergamini, S. Marini, M. Coletta, G. Maga, S. Spadari, G. Campiani, J. Med. Chem. 48 (2005) 7153-7165.

[13] A.M. McElligott, E.N. Maginn, L.M. Greene, S. McGuckin, A. Hayat, P.V. Browne, S. Butini, G. Campiani, M.A. Catherwood, E. Vandenberghe, D.C. Williams, D.M. Zisterer, M. Lawler, Cancer Res. 69 (2009) 8366-8375.

[14] S.A. Bright, A.M. McElligott, J.W. O'Connell, L. O'Connor, P. Carroll, G. Campiani, M.W. Deininger, E. Conneally, M. Lawler, D.C. Williams, D.M. Zisterer, Br. J. Cancer 102 (2010) 1474-1482.

[15] J.C. Forde, E.N. Maginn, G. McNamara, L.M. Martin, G. Campiani, D.C. Williams, D. Zisterer, A.M. McElligott, M. Lawler, T.H. Lynch, D. Hollywood, L. Marignol, Cancer Biol. Ther. 11 (2011) 421-428.

[16] M. Brindisi, C. Ulivieri, G. Alfano, S. Gemma, F.D.A. Balaguer, T. Khan, A. Grillo, G. Chemi, G. Menchon, A.E. Prota, N. Olieric, D. Lucena-Agell, I. Barasoain, J.F. Diaz, A. Nebbioso, M. Conte, L. Lopresti, S. Magnano, R. Amet, P. Kinsella, D.M. Zisterer, O. Ibrahim, J. O'Sullivan, L. Morbidelli, R. Spaccapelo, C. Baldari, S. Butini, E. Novellino, G. Campiani, L. Altucci, M.O. Steinmetz, S. Brogi, Eur. J. Med. Chem. (2018), https://doi.org/10.1016/j.ejmech.2018.11.004.

[17] G. Campiani, V. Nacci, I. Fiorini, M.P. De Filippis, A. Garofalo, S.M. Ciani, G. Greco, E. Novellino, D.C. Williams, D.M. Zisterer, M.J. Woods, C. Mihai, C. Manzoni, T. Mennini, J. Med. Chem. 39 (1996) 3435-3450.

[18] W. Reeve, C.W. Woods, J. Am. Chem. Soc. 82 (1960) 4062-4066.

[19] W. Reeve, M. Nees, J. Am. Chem. Soc. 89 (1967) 647-651.

[20] W. Reeve, E.R. Barron, J. Org. Chem. 40 (1975) 1917-1920.

[21] W. Reeve, R. Tsuk, J. Org. Chem. 45 (1980) 5214-5215.

[22] K.E. Henegar, R. Lira, J. Org. Chem. 77 (2012) 2999-3004.

[23] E.J. Corey, J.O. Link, Tetrahedron Lett. 33 (1992) 3431-3434.

[24] E.J. Corey, J.O. Link, J. Am. Chem. Soc. 114 (1992) 1906-1908.

[25] A. Ganta, J.L. Shamshina, L.R. Cafiero, T.S. Snowden, Tetrahedron 68 (2012) 5396-5405.

[26] M.S. Perryman, M.E. Harris, J.L. Foster, A. Joshi, G.J. Clarkson, D.J. Fox, Chem. Commun. 49 (2013) 10022-10024.

[27] M.K. Gupta, Z. Li, T.S. Snowden, Org. Lett. 16 (2014) 1602-1605.

[28] M.S. Perryman, M.W.M. Earl, S. Greatorex, G.J. Clarkson, D.J. Fox, Org. Biomol. Chem. 13 (2015) 2360-2365.

[29] A. Schäfer, A. Wellner, M. Strauss, A. Schäfer, G. Wolber, R. Gust, J. Med. Chem. 55 (2012) 9607-9618.

[30] N.J. Pawar, V.S. Parihar, S.T. Chavan, R. Joshi, P.V. Joshi, S.G. Sabharwal, V.G. Puranik, D.D. Dhavale, J. Org. Chem. 77 (2012) 7873-7882.

[31] K.E. Henegar, R. Lira, H. Kim, J. Gonzalez-Hernandez, Org. Process Res. Dev. 17 (2013) 985-990.

[32] C.-W. Lee, R. Lira, J. Dutra, K. Ogilvie, B.T. O’Neill, M. Brodney, C. Helal, J. Young, E. Lachapelle, S. Sakya, J.C. Murray, J. Org. Chem. 78 (2013) 2661-2669.

[33] J.R. Snider, J.T. Entrekin, T.S. Snowden, D. Dolliver, Synthesis-Stuttgart 45 (2013) 1899-1903.

[34] P.B. Koswatta, J. Das, M. Yousufuddin, C.J. Lovely, Eur. J. Org. Chem. 2015 (2015) 2603-2613.

[35] V.S. Parihar, N.J. Pawar, S. Ghosh, B. Chopade, N. Kumbhar, D.D. Dhavale, RSC Adv. 5 (2015) 52907-52915.

[36] Z. Li, M.K. Gupta, T.S. Snowden, Eur. J. Org. Chem. 2015 (2015) 7009-7019.

[37] E.J. Corey, J.O. Link, Y. Shao, Tetrahedron Lett. 33 (1992) 3435-3438.

[38] V.K. Aggarwal, A. Mereu, J. Org. Chem. 65 (2000) 7211-7212.

[39] J.M. Wyvratt, G.G. Hazen, L.M. Weinstock, J. Org. Chem. 52 (1987) 944-945.

[40] D.A. Dudley, A.M. Bunker, L. Chi, W.L. Cody, D.R. Holland, D.P. Ignasiak, N. Janiczek-Dolphin, T.B. McClanahan, T.E. Mertz, L.S. Narasimhan, S.T. Rapundalo, J.A. Trautschold, C.A. Van Huis, J.J. Edmunds, J. Med. Chem. 43 (2000) 4063-4070. 